www.jmscr.igmpublication.org

Impact Factor 5.84

Index Copernicus Value: 71.58

ISSN (e)-2347-176x ISSN (p) 2455-0450

crossref DOI: _https://dx.doi.org/10.18535/jmscr/v5i11.81

Journal Of Medical Science And Clinical Research

IGM Publication

An Official Publication of IGM Publication

\title{
Diagnostic Evaluation of Ultrasound in Detecting Breast Masses Keeping Histopathology as Gold Standard - A Hospital Based Study
}

\author{
Authors \\ Dr Niya Ann Kurien" ${ }^{1}$, Dr Viji Krishnan² \\ ${ }^{1}$ Assistant Professor, Department of Radiodiagnosis, MOSC Medical College, Kolenchery, Kerala \\ ${ }^{2}$ Associate Professor, Department of Biochemistry, JMMC\&RI, Thrissur, Kerala \\ Corresponding Author \\ Dr Viji Krishnan
}

Associate Professor, Department of Biochemistry, JMMC\&RI, Thrissur, Kerala

Email: vijikrishnandr@yahoo.in

\begin{abstract}
Background: Breast cancer is the most common female malignancy worldwide. The purpose of the study was to evaluate the worth of ultrasonography in diagnosis of symptomatic breast diseases by comparing it with mammogram using histopathology as gold standard.

Materials and Methods: Total 50 patients of breast cancer were included in this comparative study. These cases were subjected to mammography. Ultrasound was then performed as an alternate modality while clinical and mammographic results were available to the radiologist evaluating the ultrasound scans. Statistical measures of accuracy, sensitivity, specificity, positive predictive (PPV) and negative predictive values (NPV), accuracy of both mammography and ultrasound were calculated by taking histopathology as gold standard.

Results: Distribution of cases was based on clinical diagnosis and presenting symptoms was as follows: mass palpable-27(54.0\%), breast pain-20(40.0\%), with nipple discharge -7 (14.0\%), lymphnode-17(94\%), menopause-32 (64.0\%) and skin discoloration -17(34.0\%). Family history of breast cancer was also present in 27(54.0\%). The specificity of combined effect of axillary lymph node on mammogram and mammogram -mass(ill defined) and also ultrasound in predicting malignancy if pathology finding is gold standard is $100 \%$.Our data indicate that sensitivity and specificity of ultrasound was also statistically significant with mammography in patients with breast symptoms for the detection of breast cancer

Conclusion: Ultrasound can also be considered as a primary screening tool in population and as a complementary tool to mammography to minimize the chances of missing diagnosis of breast cancers.

Keywords: Breast masses, Mammography, histopathology.
\end{abstract}

\section{Introduction}

Breast cancer is the most common female malignancy worldwide. Cancers are treatable only when detected at early stage. The long term survival rate for early stage breast carcinoma is $90-98 \%{ }^{[1]}$. At present, most breast imaging is directed at early detection in order to intervene timely and reduce high mortality ${ }^{[2,3]}$. The decline in mortality rate from breast cancer observed in developed countries was largely due to early detection and treatment ${ }^{[4]}$. 
Over the years, encouraged by appreciable decrease in morbidity and mortality in breast carcinoma, mammography has become tremendously popular worldwide ${ }^{[5]}$. It has long been considered as the best screening tool for breast cancer and has the discrete capability of detecting non-palpable lesions. Mammography which uses low energy $\mathrm{x}$-rays for diagnosis is a sensitive method for detecting early breast carcinoma ${ }^{[6]}$. However, mammography has limited specificity, results in unnecessary biopsies and cannot be used effectively in resource-limited countries because of its cost ${ }^{[7]}$.

\section{Materials and Methods}

\section{Ethical Approval: Institutional Ethical}

Committee clearance was obtained. In addition, informed consent was obtained from all the patients prior to ultra sound and mammography.

Study Design: Analytical study

Inclusion Criteria: All female patients suspected or clinically diagnosed breast masses based on ultrasound and mammographic findings above 30 years (age group ranging from 31-89 years)

Exclusion Criteria: All female patients with cystic breast lesions based on ultra sound and mammographic findings and below 30 years of age.

The cancer detection rate was assessed among females in between the age of 31-89 years, over a period of 18months, from January 2013 to June 2014 under the Department ofRadiology, Jubilee Mission Medical College and Research Institute. This comprised of total of 50 patients who were evaluated for breast masses underwent mammogram, breast ultrasound. They were followed up for histopathology assessment as diagnostic gold standard. The lesions were classified as benign or malignant based on the cytopathology report. Females having history of breast mass or presenting with complaints of breast pain, nipple discharge and any associated skin change on mammography was further confirmed on ultrasound. Females having positive clinical findings but missed on mammography may be due to dense breast tissue but were picked up or enhanced when ultrasound was combined. A note was made of location and number of lesions. Any associated calcification, architectural distortion and asymmetric density was also noted. Ultrasound assessment was directed to the clinical or mammographic area of interest as well as whole breasts bilaterally. Patients were then followed for histopathology findings obtained from excisional biopsy or mastectomy specimen. The results of histopathology were taken as gold standard. Statistical software namely SPSS version 18 was used for the analysis of data. The study outcome was measured in terms of diagnostic accuracy, sensitivity, specificity, PPV (Positive predictive value) and NPV (Negative predictive value) of ultra sound and mammography keeping histopathology as gold standard. Ultrasonography was performed in all these patients using ultrasound machine LOGIQ P5 of GE.The mammography machine used was 'METALTRRONICA'. The most commonly used target-filter combination is a molybdenum (Mo) target with $0.03 \mathrm{~mm}$ Molybdenumfilter.

\section{Results}

In this study the mean age of the participants was 50.0 with SD +11.2 years (Table 1). The maximum number of lesions were seen in the age group of $<50$ years i.e. $54 \%$.

\begin{tabular}{|c|c|c|}
\hline \multicolumn{2}{|l|}{$\begin{array}{c}\text { Percentage Distribution of the Sample } \\
\text { According to Age (Table 1) }\end{array}$} \\
\hline Age & Count & Percent \\
\hline$<50$ & 27 & 54.0 \\
\hline$>=50$ & 23 & 46.0 \\
\hline Mean \pm SD & \multicolumn{3}{|c|}{$50 \pm 11.2$} \\
\hline
\end{tabular}

Based on histopathology, out of 50 patients with breast symptoms, 21 patients had benign lesions, whereas 29 patients were diagnosed as the cases of breast cancers (Table 2).Chi square test (50) and $\mathrm{p}$ value $(0.00)$ are $100 \%$ significant in comparing clinical diagnosis with pathological findings. 
Percentage Distribution Of Sample According To Clinical Diagnosis And Comparison Based On Pathological Findings (Table 2)

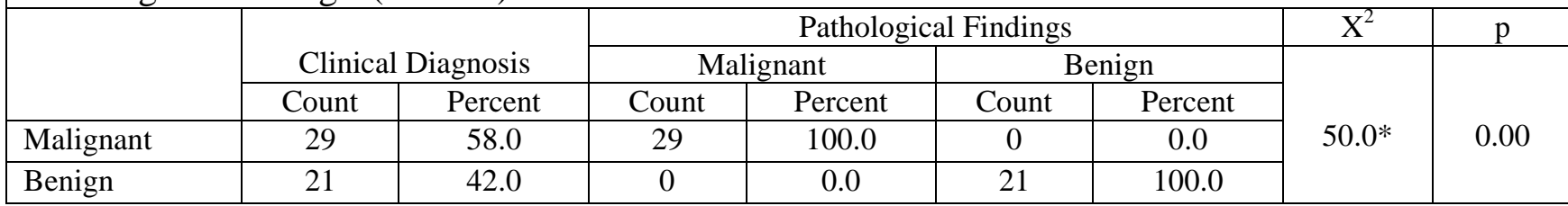

Among the study subjects, 27 had palpable masses $(54.0 \%)$ and $7(25.9 \%)$ (Table 3) were malignant and20(74.1\%) were benign. Outof 23 nonpalpable cases, $22(95.7 \%)$ cases were malignant and only one $(74.1 \% 0$ was benign. Chi square test $(24.79)$ and $\mathrm{p}$ value $(0.00)$ are significant in comparing palpable masses with pathological findings. Out of the 50 patients, only 20 patients $(40 \%)$ had pain and in 30 patients $(60 \%)$ pain was absent. As seen in the table3, out of 29 malignant cases, pain was absent in 27(90\%) and 2 of them (10\%) had pain. There were 21 benign cases of which, 3 patients $(10 \%)$ didn't havepain and 18 patients $(90 \%)$ had pain. Chi square test gives a value of 31.53 and p0.000 which is significant.So, significant association was seen between pain and pathological findings.

The Table 3 also shows that out of 29 malignant cases, in 25 patients $(58.1 \%)$, nipple discharge was absent and $4(57.1 \%)$ of them had nipple discharge and out of 21 benign cases, 3(42.9\%) of them had nipple discharge and $18(41.9 \%)$ of them didn't have nipple discharge. No significant association was seen between nipple discharge and pathological findings.

Out of the 18 patients in the present study having lymph node in mammogram (Table 3), 17(94.4\%) were malignant and only one was benign (5.6\%).In 32patients, lymph node in mammogram was absent, ofwhich, $12(37.5 \%)$ were malignant and 20 cases $(62.5 \%)$ were benign. Kappa gives a value of 0.5 which gives moderate agreement and $p$ value 0.000 which is also significant.

From the Table 3 we can see that, out of 50 patients, $18(36 \%)$ has not attained menopause and $32(64 \%)$ has attained menopause. The Chi-square test gives a value of 2.12 and $\mathrm{p} 0.145$ which is also not significant. No significant association was seen between menopause and pathological findings.

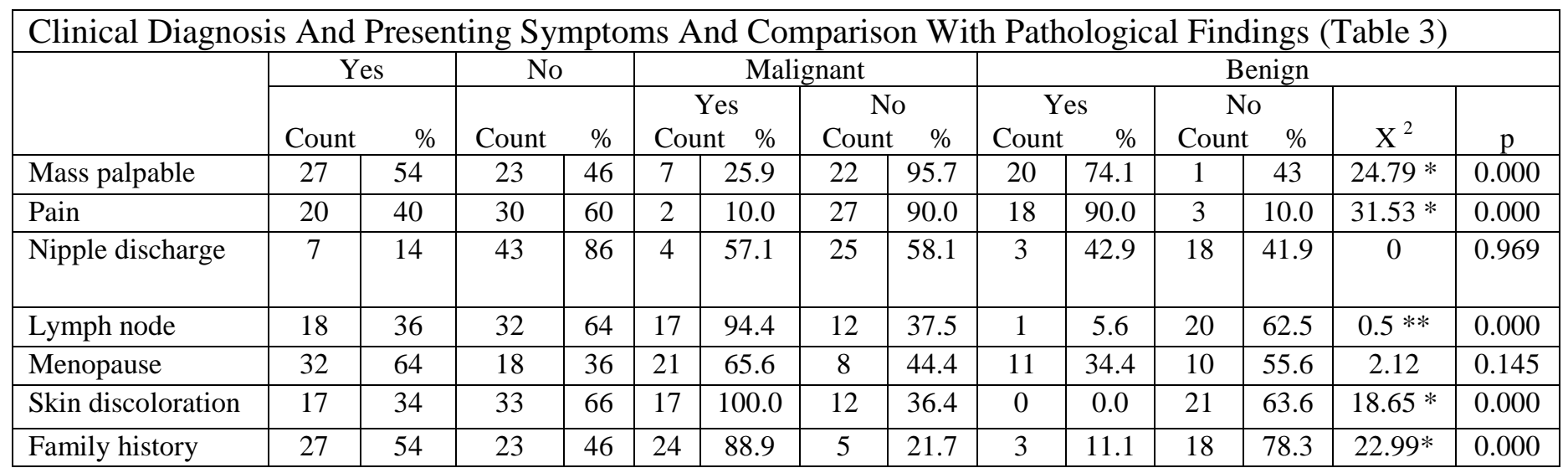

*:-Significant at 0.01 level $* *$-moderate agreement 
Out of 50 patients, 33(66\%) had no skin discoloration and 17 patients $(34 \%)$ had skin discoloration. There were 29 malignant cases out of which $12(36.4 \%)$ of them doesn't have skin discoloration and 17(100\%) of them had skin discoloration and out of 21 benign cases, none of them (63.6\%) had skin discoloration.Chi square test and $\mathrm{p}$ value are significant which are 18.65 and 0.000 respectively, which shows that there is significant association between skin discoloration and pathological findings (Table 3). Among the 50 patients who were examined, 23 didn't have any family history of breast cancer and 27 had family history of breast cancer. From the table 3, we can see that 24(88.9\%) out of 29 malignant cases had relevant family history and rest $5(21.7 \%)$ had no family history of breast cancer (Table 3).Out of 21 benign cases, 3(11.1\%) of them had relevant family history and 18(78.35) had no family history. Chi square test gives a value of 22.99 and p 0.000 which is significant. So significant association was seen between family history and pathological findings.

50 patients were grouped based on the affected side. The table indicates (Table 4) indicates that out of 36 left sided breast masses ,25 (69.4\%)

\begin{tabular}{|c|c|c|c|c|c|c|c|c|}
\hline \multicolumn{9}{|c|}{ Table 4} \\
\hline \multirow{2}{*}{\multicolumn{3}{|c|}{$\begin{array}{l}\text { Distribution of } \\
\text { sample according } \\
\text { to affected side }\end{array}$}} & \multicolumn{6}{|c|}{$\begin{array}{l}\text { Comparison of affected side } \\
\text { pathological findings }\end{array}$} \\
\hline & & & \multicolumn{2}{|c|}{ Malignant } & \multicolumn{2}{|c|}{ Benign } & \multirow[b]{2}{*}{$\mathrm{X}^{2}$} & \multirow{2}{*}{$P$} \\
\hline & Count & $\%$ & Count & $\%$ & Count & $\%$ & & \\
\hline eft & 36 & 72 & 25 & 69.4 & 11 & 30.6 & $6.91 *$ & 0.009 \\
\hline Right & 14 & 28 & 4 & 28.6 & 10 & 71.4 & & \\
\hline
\end{tabular}

were malignant and 11(30.6\%) were benign. There were 14 masses which affected right breast, of which 4(28.6\%) were malignant and 10(71.4 $\%)$ were benign. The Chi-square test gives a value of $6.91, \mathrm{p} 0.009$, which proves that there is higher incidence of malignancy on left side more than that on the right.

Based on the quadrant affected, (Table 5) out of the 50 cases, 34 participants (68\%) had lesion in upper quadrant, 29(85.3\%) were malignant and $5(14 \%)$ were benign. All 9 cases in upper inner quadrant were benign i.e. $100 \%$ and all $7 \%$ (100 $\%)$ cases in inner lower quadrant were also benign. The Chi-square test gives a value of 32.49 , p 0.000 , which is also significant proving that there is higher incidence of malignancy in upper outer quadrant.

\begin{tabular}{|l|c|c|c|c|c|c|c|c|}
\hline Table 5 \\
\hline \multicolumn{10}{|c|}{$\begin{array}{c}\text { Percentage distribution of sample } \\
\text { according to affected quadrant }\end{array}$} & \multicolumn{7}{|c|}{ Comparison based on pathological findings } \\
\cline { 5 - 9 } & Malignant & \multicolumn{3}{|c|}{ Benign } & & \\
\hline Quadrant & Count & $\%$ & Count & $\%$ & Count & $\%$ & $\mathrm{X}^{2}$ & $\mathrm{p}$ \\
\hline Upper Outer & 34 & 68.0 & 29 & 85.3 & 5 & 14.7 & 32.49 & 0.000 \\
\hline Upper Inner & 9 & 18.0 & 0 & 0.0 & 9 & 100.0 & & \\
\hline Inner Lower & 7 & 14.0 & 0 & 0.0 & 7 & 100.0 & & \\
\hline
\end{tabular}

\begin{tabular}{|c|c|c|c|c|}
\hline \multicolumn{5}{|c|}{ Mammographic findings in predicting malignancy if pathology is gold standard } \\
\hline Parameter & $\begin{array}{c}\text { Mammogram } \\
- \\
\text { mass }\end{array}$ & $\begin{array}{c}\text { Mammogram } \\
\text { LN\&Mammogram-mass } \\
\text { (Ill defined) }\end{array}$ & $\begin{array}{l}\text { Micro calcification } \\
\& \text { mammogram mass } \\
\text { (Ill defined) }\end{array}$ & $\begin{array}{c}\text { Mammogram LN, Micro } \\
\text { calcification \& Mammogram } \\
\text { mass (Ill defined) }\end{array}$ \\
\hline Sensitivity & 89.7 & 51.7 & 62.1 & 44.8 \\
\hline Specificity & 90.5 & 100.0 & 100.0 & 100.0 \\
\hline $\begin{array}{l}\text { Positive Predictive value } \\
\text { (PPV) }\end{array}$ & 92.9 & 100.0 & 100.0 & 100.0 \\
\hline $\begin{array}{l}\text { Negative Predictive value } \\
\text { (NPV) }\end{array}$ & 86.4 & 60.0 & 65.6 & 56.8 \\
\hline Accuracy & 90.0 & 72.0 & 78.0 & 68.0 \\
\hline kappa & $0.8 *$ & $0.47 *$ & $0.58 *$ & $\begin{array}{c}0.41 * \\
* \text { Significant at } 0.01 \text { level }\end{array}$ \\
\hline
\end{tabular}




\begin{tabular}{|c|c|c|c|c|c|c|c|}
\hline \multicolumn{8}{|l|}{$\begin{array}{l}\text { Table } 7 \\
\text { USG findin }\end{array}$} \\
\hline Parameter & $\begin{array}{l}\text { USG- } \\
\text { mass }\end{array}$ & $\begin{array}{c}\text { USG } \\
\text { LN\& } \\
\text { USG- } \\
\text { mass } \\
\text { (Ill } \\
\text { defined) }\end{array}$ & $\begin{array}{c}\text { Echogenicit } \\
\text { y } \\
\text { (mixed) } \\
\text { \& USG - } \\
\text { mass } \\
\text { (Ill defined) }\end{array}$ & $\begin{array}{c}\text { USG } \\
\text { calcificatio } \\
n \text { \& } \\
\text { USG- mass } \\
\text { (Ill } \\
\text { defined) }\end{array}$ & $\begin{array}{c}\text { USG LN, } \\
\text { Echogenicity } \\
\text { (mixed),USG } \\
\text { calcification } \\
\text { \&USG-mass } \\
\text { (Ill defined) }\end{array}$ & $\begin{array}{l}\text { USG-mass(Ill } \\
\text { defined) } \\
\text { \&pseudo } \\
\text { capsule } \\
\text { (absent) }\end{array}$ & $\begin{array}{c}\text { USG-mass } \\
\text { (Ill } \\
\text { defined)\& } \\
\text { shape on } \\
\text { USG } \\
\text { (taller) }\end{array}$ \\
\hline Sensitivity & 100.0 & 58.6 & 96.6 & 65.5 & 44.8 & 100.0 & 100.0 \\
\hline Specificity & 90.5 & 100.0 & 95.2 & 100.0 & 100.0 & 95.2 & 95.2 \\
\hline $\begin{array}{l}\text { Positive Predictive } \\
\text { value(PPV) }\end{array}$ & 93.5 & 100.0 & 96.6 & 100.0 & 100.0 & 96.7 & 96.7 \\
\hline $\begin{array}{l}\text { Negative Predictive } \\
\text { value(NPV) }\end{array}$ & 100.0 & 63.6 & 95.2 & 67.7 & 56.8 & 100.0 & 100.0 \\
\hline Accuracy & 96.0 & 76.0 & 96.0 & 80.0 & 68.0 & 98.0 & 98.0 \\
\hline kappa & $0.92^{*}$ & $0.54 *$ & $0.92 *$ & $0.61 *$ & $0.41^{*}$ & $0.959^{*}$ & $0.959 *$ \\
\hline
\end{tabular}

The above table (Table 6, Graph 1)) shows that mammogram findings in predicting malignancy if pathology is gold standard is significant ; where specificity of combined effect of axillary lymph node on mammogram and mammogram-mass(ill defined) is $100 \%$, that of combination of microcalcification and mammogram-mass(illdefined) is $100 \%$ and combination of axillary lymph node on mammogram, microcalcification and mammogram-mass (ill defined) is also 100 $\%$.

The sensitivity, specificity, positive predictive (PPV) and negative predictive values (NPV), accuracy of mammogram findings were compared with pathological findings. The mammogram findings which were compared were-mass on mammogram, combination of axillary lymph node and mass(ill-defined),combination of micro calcification and mammogram-mass(ill-defined), combination of mammogramlymph node, micro calcification and mammogram-mass(ill defined).

The ultrasound findings which were mass on ultra sound; ultra sound lymph node \& ultra sound -mass(ill-defined); echogenicity (mixed) and ultrasound lymph node, echogenicity (mixed), ultra sound calcification and ultra sound-mass(Ill defined);ultra sound- mass \&pseudocapsule,ultra sound -mass \&shape on ultra sound. The above table (Table 7, Graph 2) shows that ultra sound in predicting malignancy if pathology finding is gold standard is significant. The sensitivity of mass on ultra sound is $100 \%$ that of combination of ultra sound-mass (ill defined) and pseudo capsule (absent); ultrasound-mass (ill- defined) \& shape on ultra sound (taller) are also $100 \%$ sensitive. The specificity of combined effect of ultra sound lymph node \& ultra sound-mass(ill defined) is $100 \%$,that of combination of ultra sound calcification \&ultra sound -mass (ill defined); ultra sound lymph node , echogenicity (mixed), ultra sound calcification \&ultrasoundmass(ill-defined) are also $100 \%$.The Positive Predictive value of combined effect of ultra sound calcification \& ultra sound-mass (ill defined); ultrasound lymphnode, echogenicity (mixed),ultra sound calcification \&ultra sound -mass (ill defined) are also $100 \%$. 
Mammographic findings in predicting malignancy if histopathology is gold standard (Graph 1)

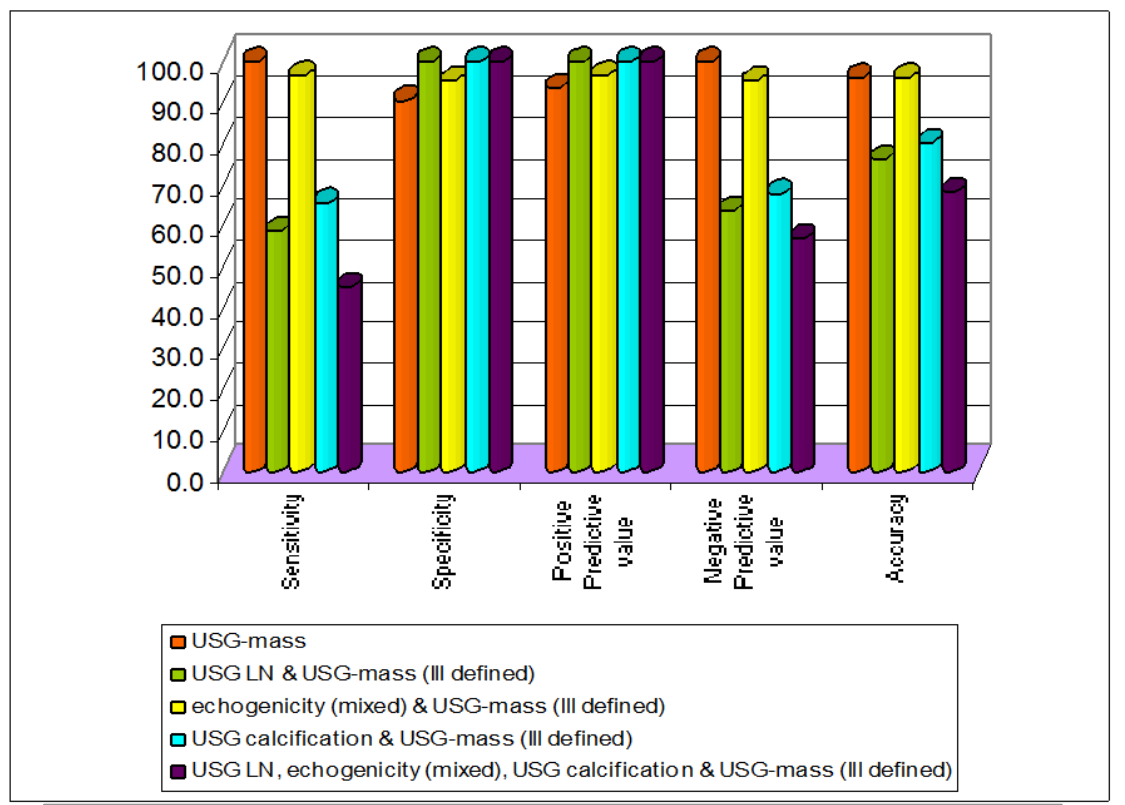

Ultrasongraphic findings in predicting malignancy if histopathology is gold standard (Graph 2) 


\section{Discussion}

Women who present with breast symptoms or who have palpable findings on clinical examination are usually investigated with breast imaging, which generally consists of mammography or breast ultrasound or both. Results of present study indicate that the combination of ultrasound and mammography yielded enhanced sensitivity, specificity and diagnostic accuracy in the diagnostic evaluation of breast cancer

The current study was conducted to establish the efficacy of breast ultrasound in evaluation of symptomatic breast diseases especially palpable breast lumps in comparison with mammography taking histopathology as gold standard. The overall sensitivity of ultrasound in diagnosing malignant lesions was $100 \%$, which is better than the sensitivity of mammogram.

Berg and Gilbreath ${ }^{[8]}$ demonstrated that wholebreast sonography would be a useful complement to mammography in the pre-operative evaluation of patients with breast cancers, providing a more accurate assessment of disease extent. Also the future role of sonography in breast imaging was suggested by American College of Radiology ${ }^{[9]}$.

Ultrasonography does not utilize ionizing radiation and has many advantages of being affordable, readily available repeatable, sensitive and a pre-interventional tool ${ }^{[7]}$. Evidence suggests that in the case of a palpable lump, breast ultrasound should be the preferred imaging procedure, leading to a definitive diagnosis with an additional consecutive core needle biopsy. It should be mandatory for women without symptoms, and complementary to mammography in the case of dense breast. Adjunctive ultrasound assessment improves breast cancer detection in women of all ages and should be routinely used in symptomatic breast clinics ${ }^{[10]}$.

If there is lesion on mammogram, complimentary ultrasound can be done for characterization of lesion and if there is suspicious lesion either on ultrasound or mammogram, biopsy should be taken. Also if mammogram is inconclusive or there is asymmetry, ultrasound should be the next step to exclude a mass lesion. Itis important here to understand that ultrasound should be integral part of breast imaging.

\section{Conclusion}

Though for many years the utility of breast ultrasound was limited to differentiate between solid and cystic lesions, with the availability of high resolution technique the breast ultrasound has assumed an important role. There is no radiation risks associated with breast ultrasound. Ultrasound is very good if the lesion is palpable. It is also goodwhen mammogram is inconclusive or Unremarkable despite of the clinical suspicion of breast pathology. This study showed that ultrasound has high sensitivity in differentiation of benign and malignant lesions and also in combination with mammography. So it should be considered as an important screening and diagnostic alternative to mammography in younger population as well as in elder women to minimize the chances of missing diagnosis of breast cancers.

\section{Acknowledgements}

This research was conducted as a part of dissertation at Jubilee Mission Medical College \& Research Institute (JMMC\&RI), Thrissur, Kerala. The author thanks Dr. M.R. Balachandran Nair, Head of the Department of Radio diagnosis (JMMC \&RI) and other colleagues from JMMC\& RI for their valuable suggestions. The author also wants to thank the patients for their cooperation without which this work would not have been completed.

Source of support: Funded by the institution

\section{Bibliography}

1. Jemal A, Murray T, Ward E, Samuels A, Tiwari RC, Ghafoor A, et al. Cancer statistics 2005. CA Cancer J Clin 2005;55:10-30. 
2. Rahbar G., A.C. Sie, G.C. Hansen, J.S Prince ,M.L. Melany, H.E. Reynold, V.P. Jackson, J.W. Sayre and L.W. Bassett. Benign versus malignant solid breast masses: US differentiation. Radiology 1999; 213: 889-894.

3. Dennis M, S.H. Parker, A.J. Klaus, T.A, Stavros T.I, Kaske and S.B. Clark. Breast Biopsy Avoidance: The Value of normal mammograms and normal sonograms in the setting of a palpable lump.Radiology 2001;219: 186-191.

4. Okobia, M.N., C.H. Bunker, F.E. Okonofua and U. Osime, 2006. Knowledge, attitude and practice of Nigerian Women towards breast cancer: a cross-sectional study. World Journal of surgical Oncology 2006 ;4: Doi: 10, 1186/1477-7819-4-11.

5. Ryan S, Mc Nicholas $M$, Eustace $S$. Anatomy for diagnostic imaging. Spain: Saunders publishers; 2004; p.30713.

6. Tabar L., G. Fagerberg, S.W. Duffy N.E, Day A. Gad and O. Grontoft. Update of the Swedish two-country program of mammographic screening for breast cancer. Radio Clin North Am 1992;30: 187-201.

7. Shyyan R, R.S. Masood, R.A. Badwe, K.M. Errico L. Liberman, V. Ozmen, H. Stalsberg, H. Vagas and L. Vass. Breast cancer in limited-resource countries: diagnosis and pathology. The Breast Journal 2006 ;12 suppl.1: 27-37.

8. Berg,W and P. Gilbreath. Multicentric and multifocal cancer: Whole-breast US in preoperative evaluation. Radiology 200; 214: 59-66.

9. American College of Radiology (ACR). Breast Imaging reporting and data system (BI-RADS)- 2 ed. Reston, Va: American College of Radiology,2003.
10. Hille H, Vetter M, Hackelöer BJ .Reevaluating the role of breast ultrasound in current diagnostics of malignant breast lesions.2004; 25(6):411-17. 